Sports Science

\title{
Estimated energy expenditure and training intensity in young female artistic gymnasts
}

\author{
Karine Naves de Oliveira Goulart ${ }^{1}$ (D), Márcio Mário Vieira ${ }^{2}$ (D), \\ Ivana Montandon Soares Aleixo $^{2}$ (D), Carolina Franco Wilke ${ }^{1,3}$ (D), Samuel Penna Wanner ${ }^{1}$ \\ ${ }^{1}$ Universidade Federal de Minas Gerais, Escola de Educação Física, Fisioterapia e Terapia \\ Ocupacional, Laboratório de Fisiologia do Exercício, Belo Horizonte, MG, Brazil. ${ }^{2}$ Universidade \\ Federal de Minas Gerais, Escola de Educação Física, Fisioterapia e Terapia Ocupacional, \\ Departamento de Esportes, Belo Horizonte, MG, Brazil. ${ }^{3}$ Centro Unificado de Identificação e \\ Desenvolvimento do Atleta de Rendimento, Clube de Regatas do Flamengo, Rio de Janeiro, RJ, \\ Brazil.
}

Associate Editor: Iane de Paiva Novais (D), Universidade Estadual do Sudoeste da Bahia, Jequié. BA, Brazil. E-mail: ianepaiva@yahoo.com.br.

\begin{abstract}
Aim: This study determined the energy expenditure and effort intensity of athletes during women's artistic gymnastics training sessions. Methods: Ten gymnasts (age 10.9 \pm 1.7 years) performed a test to estimate the maximum rate of oxygen uptake $\left(\mathrm{VO}_{2 \max }\right)$, during which the maximum heart rate $\left(\mathrm{HR}_{\max }\right)$ was also obtained. The heart rate (HR) of these gymnasts was recorded during five training sessions and then used to estimate the exercise intensity and energy expenditure. Results: Mean duration of training sessions was $4.08 \pm 0.42 \mathrm{~h}$, with mean HR corresponding to $137 \pm 8$ bpm or $69.0 \pm 3.5 \%$ of $\mathrm{HR}_{\max }$. Gymnasts spent less training time at $90-100 \% \mathrm{HR}_{\max }$ compared to the other $\mathrm{HR}$ ranges $(\mathrm{p}<0.05)$. Time spent at $60-70 \%$ and $70-80 \%$ was higher compared to $80-90 \% \mathrm{HR}_{\max }(\mathrm{p}=0.012$ and $\mathrm{p}=0.001$, respectively). The training impulse was $239.2 \pm 35.4$ AU. Estimated energy expenditure was $768.3 \pm 168.5 \mathrm{kcal}$, metabolic rate was $3.1 \pm 0.6 \mathrm{kcal} / \mathrm{min}$, and the metabolic equivalent of task (MET) corresponded to $6.1 \pm 0.6$. Conclusion: Young gymnasts performed prolonged and moderate-intensity training sessions that generated high energetic demands. This information is beneficial to gymnasts since the coaching team can use the data to control the training load and prescribe a proper diet.
\end{abstract}

Keywords: energy expenditure, effort intensity, TRIMP, training sessions, women's artistic gymnastics.

\section{Introduction}

Women's artistic gymnastics (WAG) is an individual sport where athletes perform routines on four apparatuses: vault, uneven bars, balance beam, and floor ${ }^{1}$. Vault requires explosive force generation, uneven bars demand upper body strength for release and catch movements, beam requires balance and artistry, and floor demands the generation of leg impulse for tumbling alongside artistry for linking movements ${ }^{2}$. Therefore, female gymnasts must develop sport-specific physical and motor abilities and technical skills ${ }^{3}$. Also, they usually present specific anthropometric characteristics, such as reduced body mass and height as well as high levels of muscular strength, power, and flexibility ${ }^{4,5}$. Altogether, these characteristics favor performance in specific skills of artistic gymnastics ${ }^{5,6}$. Although artistic gymnastics is one of the most popular Olympic sports, there are few studies about its physiological demands ${ }^{3}$, particularly few studies including young (i.e., child and adolescent) female gymnasts ${ }^{1,5,7}$.
Training sessions in WAG usually consist of a warmup and routine training on the apparatuses, alongside strength-building and stretching exercises ${ }^{7}$. Depending on the time of the season, WAG sessions often also consist of special element/skill training. A gymnast focuses on a technicality and commonly completes many repetitions and combinations of skills during prolonged training sessions $^{2,4}$. For example, Brazilian gymnasts train 2 to 6 times per week, on average 12 to $24 \mathrm{~h}$ per week, 1.0 to $6.5 \mathrm{~h}$ per training session, depending on the athlete's competition level ${ }^{8}$. Due to the specificity of each apparatus and the long training routines, quantifying and monitoring training load are essential for coaches to help gymnasts achieve optimal performance. Further, ensuring a proper load distribution is required during periodization, aiming to reach the best performance in the most important competitions $^{8,9}$.

Valuable data that enable better control of training loads can be obtained through monitoring the heart rate (HR). For example, Marina and Rodriguez ${ }^{10}$ examined the 
HR of gymnasts in competition routines, though this study lacks investigation about training sessions. Among these important data, the energy expenditure of the gymnasts should be highlighted. A previous study showed that $\mathrm{HR}$ is valid to estimate the rate of oxygen uptake $\left(\mathrm{VO}_{2}\right)$ during intermittent aerobic exercise ${ }^{11}$. These authors reported $71 \%$ of the $\mathrm{HR}$ variance was explained by $\mathrm{VO}_{2}$ variations when these measurements were obtained during a soccer match and using a portable gas analyzer ${ }^{11}$. Thus, the HR$\mathrm{VO}_{2}$ relationship could be applied during prolonged gymnastics training sessions, where the intermittent aerobic nature is also evident. Further, data on the energy cost of WAG training sessions are necessary to update the Compendium of Physical Activities ${ }^{12}$, a resource for classifying the energy cost of human physical activities.

Thus, the knowledge about the intensity of effort and energy expenditure during WAG training sessions is crucial for prescribing adequate training loads and respective nutritional intake, thereby ensuring good health status in young female gymnasts. The excessive preoccupation with maintaining a reduced body mass can lead to a weakened nutritional status that, associated with high-intensity training, can delay the age at menarche ${ }^{13}$. Moreover, the HR response can provide coaches with a guideline for adequate WAG training and a more integrated view of the training sessions' monitoring process. Therefore, this study aimed to determine the exercise intensity and estimate the energy expenditure of young Brazilian gymnasts during WAG training sessions.

\section{Methods}

\section{Participants}

A total of 10 female gymnasts (age $10.9 \pm 1.7$ years, body mass $31.2 \pm 6.8 \mathrm{~kg}$, height $134.6 \pm 10.9 \mathrm{~cm}$, body fat $12.5 \pm 2.0 \%$ ) took part in this study. The gymnasts were involved in systematic training of WAG for at least 5 years before this study and had already participated in national competitions. This group of athletes was aimed at initial elite training. The gymnasts trained, on average, $20 \mathrm{~h}$ per week (i.e., five sessions lasting $4 \mathrm{~h}$ each during the weekdays).

This study was approved by the Research Ethics Committee of the local university (approval reference number: 32008814.4.0000.5149) and was conducted under the policies established by the Brazilian National Health Council (Resolution 416/12) for research with humans. A legal representative of each child/adolescent gymnast signed a written consent form confirming he/she was aware of the objectives and procedures that would be performed. The gymnasts signed a written informed assent form, written in the appropriate language according to their age, and were informed they could leave the study at any time, without the need to justify their decision to researchers.

\section{Experimental design}

Initially, anthropometric measurements were obtained, and the gymnasts performed the multistage $20-\mathrm{m}$ shuttle run test to estimate their maximum rate of oxygen consumption $\left(\mathrm{VO}_{2 \max }\right)^{14}$, during which the maximum heart rate $\left(\mathrm{HR}_{\max }\right)$ was also recorded (Table 1$)$. Then, the HR measurements were obtained in five training sessions per athlete (Polar Electro Oy®, Polar Team System, Finland). Data collection occurred between February and May, in the preparatory phase for the national competition (August), the seasons' main competition for these athletes. Most training sessions consisted of three main parts: general and specific warm-up, alongside basic acrobatic movements; (2) routine training on the apparatuses; (3) strength and conditioning, with strength-building and stretching exercises. Some sessions also included ballet exercises.

\section{Body composition evaluation}

The percent body fat was estimated according to the equation proposed by Slaughter et al. ${ }^{15}$, with measures obtained at two sites (i.e., subscapular and triceps) through a skinfold caliper (Lange, Cambridge Scientific Industries, Watertown, MA, USA).

\section{Assessment of the maximum rate of oxygen uptake}

During the multistage $20-\mathrm{m}$ shuttle run test ${ }^{14}$, the gymnasts used a chest strap to monitor their HR and ran as long as possible over a distance of $20 \mathrm{~m}$ demarcated by cones at the speed indicated by a recorder. A beep warned when gymnasts should be at one end or another extremity of the $20-\mathrm{m}$ track. The test was interrupted when the ath-

Table 1 - Anthropometric and physiological characteristics of the athletes.

\begin{tabular}{lccccccc}
\hline & Age (years) & Weight (kg) & Height (cm) & Body fat (\%) & $\boldsymbol{\Sigma}_{\text {skinfold }}(\mathbf{m m})$ & $\mathbf{V O}_{\mathbf{2 m a x}}\left(\mathbf{m L . k g}^{\mathbf{- 1}} \cdot \mathbf{m i n}^{\mathbf{- 1}}\right)$ & $\mathbf{H R}_{\mathbf{m a x}}(\mathbf{b p m})$ \\
\hline Mean & 10.9 & 31.2 & 134.6 & 12.5 & 12.9 & 40.0 & 199 \\
SD & 1.7 & 6.8 & 10.9 & 2.0 & 2.0 & 3.5 & 8 \\
CV (\%) & 15.9 & 21.7 & 8.1 & 15.9 & 15.3 & 9.7 & 4 \\
Minimum & 9.0 & 24.7 & 120.5 & 8.4 & 9.0 & 16.0 & 185 \\
Maximum & 14.0 & 47.1 & 156.5 & 15.5 & 16.0 & 44.9 & 209 \\
\hline
\end{tabular}

$\overline{\mathrm{CV}}=$ coefficient of variation, $\mathrm{HR}_{\max }=$ maximum heart rate, $\mathrm{SD}=$ standard deviation, $\mathrm{VO}_{2 \max }=$ maximum rate of oxygen uptake. 
lete could not reach the cone within the predetermined time for two consecutive beeps or when the athlete herself voluntarily decided to stop the exercise ${ }^{14}$. The HR was recorded by the evaluator every min during the test and when each athlete has fatigued. The $\mathrm{HR}_{\max }$ of each gymnast was the highest HR value recorded during the test.

\section{Training heart rate measure}

The HR was continuously recorded throughout five training sessions per athlete (Polar Electro Oy®, Polar Team System, Finland). The use of this equipment allows the HR recording while training without using a wrist monitor, which ensures the completion of all movements without restrictions and avoids risks to the physical integrity of gymnasts and coaches. Subsequently, the data stored were transferred to a computer through an interface, cataloged, and analyzed using the Polar Precision Performance SW (version 3.0) software.

All training sessions were conducted indoors, in the afternoon, and the environmental conditions were monitored using a thermo-hygrometer (Alla France, ChemilléMelay, France). The wet-bulb globe temperature (WBGT) was calculated using the wet- and dry-bulb temperatures according to the following equation: WBGT $\left({ }^{\circ} \mathrm{C}\right)=0.7 \mathrm{x}$ wet-bulb temperature $+0.3 \times$ dry-bulb temperature ${ }^{16}$.

\section{Determination of the exercise intensity during training} sessions

The exercise intensity was estimated from the average of HR measurements obtained during the entire training session. The intervals between exercises, during which the gymnasts placed ice on body regions where they felt pain or engaged in atypical activities, such as physiotherapy sessions and break for snacks, were not excluded from the analysis to maximize data's ecological validity. The training sessions usually ended with a conversation between the coach and gymnasts. The training duration corresponds to the time elapsed between the beginning and end of the session, including the final coach feedback.

The exercise intensity (i.e., percentage of the $\mathrm{HR}_{\max }$ ) was calculated by dividing the average HR value obtained during the training session by the $\mathrm{HR}_{\max }$ attained during the $\mathrm{VO}_{2 \max }$ test $(20-\mathrm{m}$ shuttle run test). The exercise intensity expressed as the percentage of the $\mathrm{VO}_{2 \max }$ was obtained from the direct relationship between the percentages of the $\mathrm{HR}_{\max }$ and $\mathrm{VO}_{2 \max }{ }^{17-19}$.

Energy expenditure (kcal) and metabolic rate $\left(\mathrm{kcal} . \mathrm{min}^{-1}\right)$ were estimated from the oxygen uptake values. The metabolic equivalent of task (MET) was obtained by dividing the $\mathrm{VO}_{2}$ values in $\mathrm{mLO}_{2} \cdot \mathrm{kg}^{-1} \cdot \mathrm{min}^{-1}$ by $3.5 \mathrm{mLO}_{2} \cdot \mathrm{kg}^{-1} \cdot \mathrm{min}^{-1}$. The total energy expenditure of each athlete was then calculated by multiplying the body mass $(\mathrm{kg})$ by the exercise intensity (expressed in multiples of MET; each MET corresponds to $1 \mathrm{kcal} \cdot \mathrm{kg}^{-1} \cdot \mathrm{h}^{-1}$ ) and by the training session duration $(\mathrm{h})^{17}$. Because energy supply depends predominantly on the aerobic pathway in physical exercises lasting more than two minutes ${ }^{20}$, the $\mathrm{HR}-\mathrm{VO}_{2}$ relationship is a valid method to estimate energy expenditure during prolonged training sessions and intermittent activities ${ }^{11,18,19,21,22}$.

Further, to determine the internal training load, quantified by the training impulse (TRIMP), the accumulated training duration in five $\mathrm{HR}$ zones relative to $\mathrm{HR}_{\max }$ was multiplied by a coefficient for each zone, according to Edwards ${ }^{23}$.

$$
\begin{gathered}
\operatorname{TRIMP}(\mathrm{AU})=(\mathrm{Dz} 1 \times 1)+(\mathrm{Dz} 2 \times 2)+ \\
(\mathrm{Dz} 3 \times 3)+(\mathrm{Dz} 4 \times 4)+(\mathrm{Dz} 5 \times 5)
\end{gathered}
$$

where $\mathrm{Dz} i$ is the duration in zone i. zone $1=50-60 \%$ $\mathrm{HR}_{\max }$; zone $2=60-70 \% \mathrm{HR}_{\max }$; zone $3=70-80 \% \mathrm{HR}_{\max }$; zone $4=80-90 \% \mathrm{HR}_{\max }$; zone $5=90-100 \% \mathrm{HR}_{\max }$.

\section{Statistical analyses}

Shapiro-Wilk tests were used to verify the data normality. Mauchly's test was consulted, and the Greenhouse-Geisser correction was applied if sphericity was violated. All the data regarding environmental conditions, athlete's anthropometric and physiological characteristics, training intensity, energy expenditure, and TRIMP are presented as mean \pm standard deviation (SD). The coefficient of variation $(\mathrm{CV})$ and the maximum and minimum values of the parameters listed above were also presented to ensure a complete descriptive analysis of the data collected (except the environmental conditions). The percentage of total training time in different $\mathrm{HR}$ zones $\left(0-60,60-70,70-80,80-90\right.$, and $\left.90-100 \% \mathrm{HR}_{\max }\right)$ was outlined for each athlete. One-way repeated-measures analysis of variance (ANOVA) and Sidak post hoc test were used to compare the percentage of total training time at the different HR zones. The effect size was reported based on partial eta squared $\left(\eta^{2}\right)$ from the ANOVA. Data analyses were conducted in Statistical Package for the Social Sciences (SPSS version18.0, Chicago, IL, USA) and Graphpad® software (Prism5.0, San Diego, CA, USA).

\section{Results}

The training sessions were performed indoors with average WBGT and relative humidity of $22.9 \pm 1.9^{\circ} \mathrm{C}$ and $68.1 \pm 10.5 \%$, respectively. The mean training session duration was $4.08 \pm 0.42 \mathrm{~h}$.

Mean HR during the training sessions was $137 \pm$ $8 \mathrm{bpm}$, which corresponded to $69.0 \pm 3.5 \%$ of $\mathrm{HR}_{\max }$. To better understand the intensity of the gymnastic training sessions, the HR responses were separated into five ranges, namely $0-60,60-70,70-80,80-90$, and $90-100 \%$ of $\mathrm{HR}_{\max }$. The time spent at each of these ranges (i.e., the percentage of session duration) was determined for each 
athlete. Great variability in the HR responses among gymnasts was observed; for example, athlete $\# 6$ spent $7.7 \%$ of the training sessions at an HR range above $90-100 \%$ of her $\mathrm{HR}_{\max }$, whereas athlete \#1 spent only $0.6 \%$ of the training sessions at this intensity (Figure 1). Despite the great variability observed, all 10 gymnasts spent more than $60 \%$ of training duration in intensities corresponding to less than $80 \%$ of $\mathrm{HR}_{\max }$, and more than $90 \%$ of training duration in intensities lower than $90 \%$ of $\mathrm{HR}_{\max }$. Analyzing the mean values, the gymnasts spent the most and the least of the training session's duration $(30.4 \%$ and $3.7 \%)$ in intensities corresponding to $60-70 \%$ and $90-100 \%$ of $\mathrm{HR}_{\max }$, respectively (Figure 1). A significant effect was observed comparing the percentage of total training time at different ranges $[\mathrm{F}(2,13)=23.081, \mathrm{p}=0.001$, $\left.\eta^{2}=0.719\right]$. Time spent at $90-100 \% \mathrm{HR}_{\max }$ was significantly lower compared to the other four ranges ( $\mathrm{p}<0.05$ ). Furthermore, time spent at $60-70 \%$ and $70-$ $80 \%$ was significantly higher compared to $80-90 \% \mathrm{HR}_{\max }$ $(\mathrm{p}=0.012$ and $\mathrm{p}=0.001$, respectively) (Figure 2).

Energy expenditure was estimated from HR data (Table 2). The gymnasts had average energy expenditure and metabolic rate that corresponded to $768.3 \pm$ $168.5 \mathrm{kcal}$ and $3.1 \pm 0.6 \mathrm{kcal} \cdot \mathrm{min}^{-1}$, respectively; thus, the gymnastics training sessions presented a metabolic rate that was $6.1 \pm 0.6$ times the resting metabolic rate. Finally, the average TRIMP value corresponded to $239.2 \pm 35.4 \mathrm{AU}$. For a complete description of the WAG training sessions, individual data obtained for each athlete in the five training sessions are shown in Table 3.

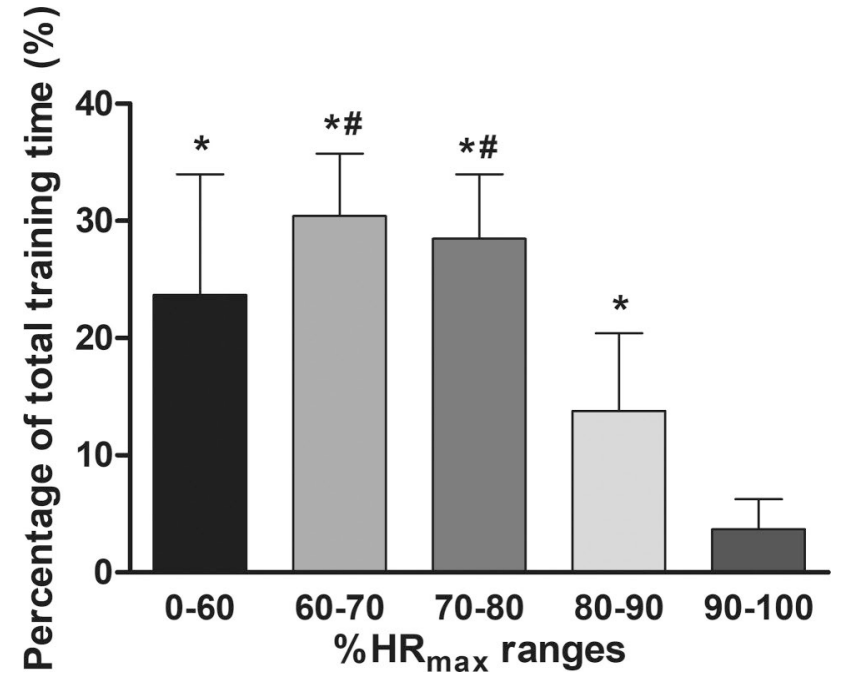

Figure 2 - Average time spent at five different exercise intensities, determined by the maximum heart rate percentage, during gymnastic training sessions. $\mathrm{HR}_{\max }=$ maximum heart rate, *means significantly different from $90-100 \% \mathrm{HR}_{\max }$, \#means significantly different from $80-90 \%$ $\mathrm{HR}_{\max }, \mathrm{p}<0.05, \mathrm{n}=10$.

\section{Discussion}

This study determined the intensity of effort and energy expenditure during artistic gymnastic training sessions. The gymnasts presented a mean absolute HR of $137 \pm 8 \mathrm{bpm}$, while relative values corresponded to $69.0 \pm 3.5 \%$ of $\mathrm{HR}_{\max }$. Furthermore, the internal load was also quantified with TRIMP values of $239.2 \pm 35.4 \mathrm{AU}$.

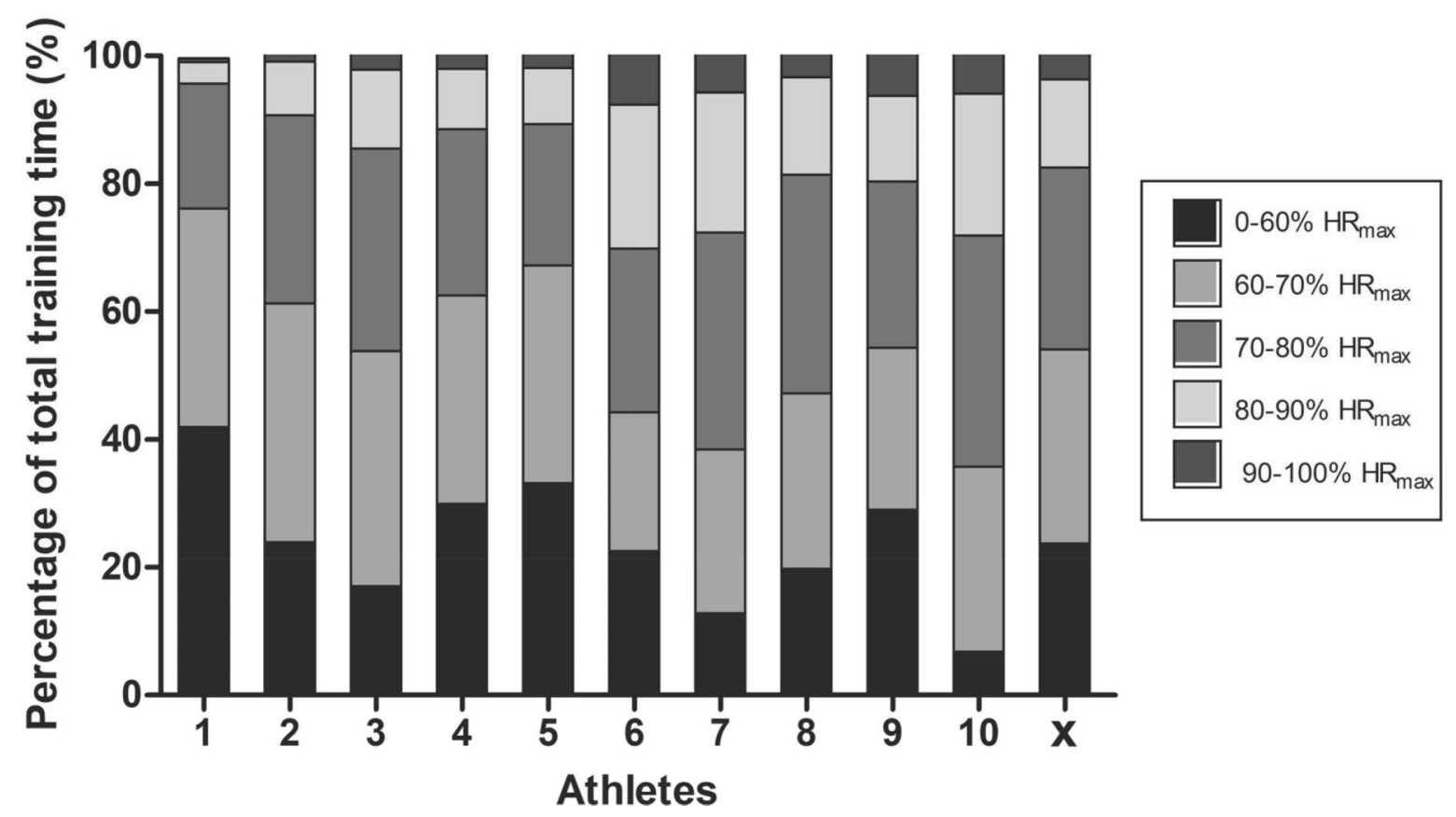

Figure 1 - Time spent at five different exercise intensities, determined by the maximum heart rate percentage, during gymnastic training sessions. Each bar represents one athlete, and the " $\mathrm{X}$ " bar represents the mean group response. $\mathrm{HR}_{\max }=$ maximum heart rate. 
Table 2 - Characterization of artistic gymnastic training sessions.

\begin{tabular}{|c|c|c|c|c|c|c|c|}
\hline & Duration (h) & HR (bpm) & $\% \mathrm{HR}_{\max }$ & EE (kcal) & Metabolic rate (kcal/min) & MET & TRIMP (AU) \\
\hline Mean & 4.1 & 137 & 69.0 & 768.3 & 3.1 & 6.1 & 239.2 \\
\hline SD & 0.4 & 8 & 3.5 & 168.5 & 0.6 & 0.6 & 35.4 \\
\hline CV (\%) & 10.3 & 6 & 5.1 & 21.9 & 20.7 & 9.3 & 15.2 \\
\hline Minimum & 2.7 & 121 & 62.8 & 589.2 & 2.3 & 5.3 & 176.0 \\
\hline Maximum & 4.9 & 149 & 74.2 & 1043.8 & 4.4 & 7.0 & 292.3 \\
\hline
\end{tabular}

$\mathrm{CV}=$ coefficient of variation, $\mathrm{EE}=$ energy expenditure, $\mathrm{HR}=$ heart rate, $\mathrm{HR}_{\max }=$ maximum heart rate, $\mathrm{MET}=$ metabolic equivalent of task, $\mathrm{SD}=$ standard deviation, TRIMP $=$ training impulse.

Gymnasts' energy expenditure was $768.3 \pm 168.5 \mathrm{kcal}$, with a metabolic rate of $3.1 \pm 0.6 \mathrm{kcal}_{\mathrm{min}} \mathrm{m}^{-1}$ or $6.1 \pm 0.6$ times resting values. Thus, the physiological demand characterization of WAG training sessions was obtained.

In the present study, HR was recorded during 5 training sessions per athlete. No other WAG study reported this variable during training sessions, making comparisons difficult. However, some studies have reported the physiological demands during simulated gymnastic competitive routines ${ }^{1,10}$. These studies showed the gymnasts reached their highest HR values (183 - $199 \mathrm{bpm})$ in the floor and uneven bars exercises, while the vault is the apparatus with the lowest HR (154 - 166 bpm $)^{10}$. Accordingly, elite French gymnasts presented the lowest mean HR values on the vault (144.5 bpm), compared to the floor (163.8 bpm), uneven bars (168.6 bpm), and balance beam $(161.8 \mathrm{bpm})^{1}$. Mean relative intensities attained during simulated competition ranged from 65 to $85 \%$ of the $\mathrm{VO}_{2 \max }$ and $\mathrm{HR}_{\max }{ }^{10}$. These values are comparatively higher than the values reported in the present study (137 bpm, 69\% of $\mathrm{HR}_{\max }$ ); however, such results should not be directly compared because rest intervals between exercises, the rest required for ice-treatment, and physiotherapy sessions during training were not excluded from analysis in the present study. Thus, our data may not elucidate the level of effort during WAG-specific exercises, even though they have the merit of characterizing the physiological demand of long training sessions (i.e., $4 \mathrm{~h}$ ), during which gymnasts obviously cannot continuously perform vigorous activities. Furthermore, due to the explosive and quasi-maximal muscle contractions required and the cardiovascular strain induced by gymnastic performance, high HR values are expected while analyzing only competitive routines ${ }^{10}$. Finally, age and training/competition levels represent different conditions between ours and previous studies.

The mean value of 6.1 MET was stated for the WAG training sessions in the present study. Data related to metabolic rate in artistic gymnastics are not included in the compendium of physical activities ${ }^{12}$. The compendium reports MET values for a wide variety of physical activities, enhancing the comparability between studies. Accordingly, in the sports category, competitive cheer- leading and gymnastic moves are described with a value of 6.0 $\mathrm{MET}^{12}$. Other sports activities with a similar MET corresponded to track and field (high jump, long jump, triple jump, javelin, and pole vault), competitive skateboard of vigorous effort, and competitive volleyball (6.0 MET for all). These data suggest that WAG training increased gymnasts' metabolic rate to values commonly observed in several other sports. Thus, metabolic rate and the resulting energy expenditure in WAG training sessions were quantified for the first time. Further, these responses were investigated in female children and teenagers, groups usually excluded from the exercise physiology and sports training studies.

The mean energy expenditure of WAG training sessions was $768.3 \mathrm{kcal}$, metabolic rate was $3.1 \mathrm{kcal}^{\mathrm{min}} \mathrm{m}^{-1}$ while TRIMP values corresponded to $239.2 \pm 35.4 \mathrm{AU}$. Of note, we could not find any study in gymnastics quantifying energy expenditure, metabolic rate, and TRIMP, making it difficult to compare our findings with data obtained in the same sport. Using a similar method, Rodrigues et al. ${ }^{24}$ estimated the metabolic rate $\left(\mathrm{kcal}_{\mathrm{min}}{ }^{-1}\right)$ and total energy expenditure (kcal) of professional futsal players during official matches. These authors reported a higher metabolic rate $\left(18.1 \mathrm{kcal} . \mathrm{min}^{-1}\right)$, though lower total energy expenditure $(313 \mathrm{kcal})$ compared to WAG training sessions. Further, during training sessions of male futsal players, Wilke et al. ${ }^{19}$ reported an energy expenditure of $846 \pm 129 \mathrm{kcal}$ and a metabolic rate of $9.3 \pm$ $1.0 \mathrm{kcal} . \mathrm{min}^{-1}$ while TRIMP values corresponded to $153 \pm 21$ AU. Previous studies monitored training session loads using TRIMP in different sports, such as female soccer $(211 \pm 81 \mathrm{AU})^{25}$, basketball $(215 \pm 109 \mathrm{AU})^{26}$, taekwondo $(114.3 \pm 13.0 \mathrm{AU})^{27}$ and swimming $(107 \pm$ $47 \mathrm{AU})^{28}$. However, comparisons between different sports are limited due to specific demands, sample characteristics, and TRIMP methods adopted in each study. Interestingly, TRIMP values were higher in gymnastics than in the studies mentioned above, which mostly included team sports, because of the long duration of gymnastic training sessions.

Participants of this study consisted of female gymnasts with a mean age of 10.9 years. Further, these gymnasts presented a low body fat $(12.5 \pm 2.0 \%)$ and a high training volume $(4.08 \pm 0.42 \mathrm{~h}$ per training session $)$, cor- 
Table 3 - Individual data for each artistic gymnastic training session.

\begin{tabular}{|c|c|c|c|c|c|c|c|c|c|c|}
\hline & A1 & A2 & $\mathbf{A 3}$ & A4 & A5 & A6 & A7 & A8 & A9 & $\mathbf{A 1 0}$ \\
\hline \multicolumn{11}{|l|}{ Average HR (bpm) } \\
\hline Session 1 & 119 & 136 & 120 & 141 & 134 & 105 & 155 & 145 & 122 & 138 \\
\hline Session 2 & 120 & 130 & 133 & 151 & 145 & 136 & 141 & 130 & 116 & 152 \\
\hline Session 3 & 127 & 138 & 140 & 147 & 141 & 126 & 156 & 141 & 138 & 149 \\
\hline Session 4 & 118 & 134 & 131 & 143 & 122 & 143 & 160 & 148 & 149 & 148 \\
\hline Session 5 & 123 & 125 & 144 & 130 & 145 & 152 & 131 & 136 & 152 & 143 \\
\hline \multicolumn{11}{|l|}{$\% \mathrm{HR} \max$} \\
\hline Session 1 & 61.7 & 69.1 & 62.6 & 65.8 & 63.9 & 56.6 & 76.6 & 72.7 & 61.9 & 69.8 \\
\hline Session 2 & 62.2 & 66.1 & 69.2 & 70.4 & 69.1 & 73.3 & 69.4 & 65.4 & 58.9 & 77.3 \\
\hline Session 3 & 65.5 & 70.0 & 72.8 & 68.6 & 67.3 & 68.3 & 76.6 & 71.0 & 70.1 & 75.7 \\
\hline Session 4 & 61.0 & 67.8 & 68.4 & 66.9 & 58.3 & 77.2 & 78.9 & 74.2 & 75.5 & 75.3 \\
\hline Session 5 & 63.7 & 63.5 & 74.8 & 60.6 & 69.6 & 82.2 & 64.3 & 68.2 & 77.3 & 72.7 \\
\hline \multicolumn{11}{|l|}{$\mathrm{EE}(\mathrm{kcal})$} \\
\hline Session 1 & 616.9 & 905.9 & 739.0 & 991.9 & 773.2 & 511.0 & 628.7 & 620.0 & 548.7 & 575.0 \\
\hline Session 2 & 614.1 & 816.4 & 1132.8 & 1162.2 & 597.6 & 938.1 & 567.2 & 536.0 & 546.6 & 817.4 \\
\hline Session 3 & 715.6 & 905.8 & 1187.6 & 1232.2 & 885.3 & 828.5 & 715.5 & 659.0 & 611.2 & 652.3 \\
\hline Session 4 & 636.3 & 873.2 & 1049.0 & 980.6 & 649.6 & 1029.6 & 627.0 & 583.9 & 758.8 & 670.4 \\
\hline Session 5 & 587.9 & 727.2 & 936.0 & 851.9 & 887.4 & 1120.2 & 539.7 & 547.3 & 669.7 & 660.4 \\
\hline \multicolumn{11}{|c|}{ Metabolic rate (kcal/min) } \\
\hline Session 1 & 2.5 & 3.8 & 3.0 & 4.3 & 3.2 & 2.1 & 2.7 & 2.5 & 2.3 & 2.5 \\
\hline Session 2 & 2.6 & 3.5 & 4.0 & 4.9 & 3.6 & 3.4 & 2.3 & 2.0 & 2.1 & 3.0 \\
\hline Session 3 & 2.9 & 3.9 & 4.0 & 4.6 & 3.5 & 3.0 & 2.7 & 2.4 & 2.9 & 2.9 \\
\hline Session 4 & 2.5 & 3.7 & 3.6 & 4.4 & 2.7 & 3.7 & 2.8 & 2.6 & 3.3 & 2.8 \\
\hline Session 5 & 2.7 & 3.3 & 4.2 & 3.7 & 3.7 & 4.1 & 2.0 & 2.2 & 3.5 & 2.7 \\
\hline \multicolumn{11}{|l|}{ MET } \\
\hline Session 1 & 5.2 & 6.9 & 5.5 & 5.5 & 5.2 & 4.5 & 6.5 & 6.0 & 5.2 & 5.4 \\
\hline Session 2 & 5.2 & 6.3 & 7.1 & 6.2 & 6.0 & 7.3 & 5.5 & 5.0 & 4.7 & 6.5 \\
\hline Session 3 & 5.8 & 7.0 & 7.2 & 5.9 & 5.8 & 6.4 & 6.5 & 5.8 & 6.5 & 6.3 \\
\hline Session 4 & 5.0 & 6.6 & 6.5 & 5.6 & 4.4 & 8.0 & 6.8 & 6.2 & 7.4 & 6.2 \\
\hline Session 5 & 5.5 & 5.9 & 7.6 & 4.7 & 6.1 & 8.8 & 4.8 & 5.4 & 7.7 & 5.8 \\
\hline \multicolumn{11}{|l|}{ TRIMP } \\
\hline Session 1 & 167.0 & 240.0 & 174.0 & 209.5 & 189.6 & 122.3 & 314.7 & 275.4 & 169.1 & 249.3 \\
\hline Session 2 & 170.9 & 210.4 & 241.0 & 255.4 & 241.5 & 284.9 & 244.2 & 204.0 & 138.9 & 323.0 \\
\hline Session 3 & 196.1 & 250.4 & 278.9 & 236.4 & 220.9 & 231.5 & 314.4 & 259.1 & 251.0 & 307.6 \\
\hline Session 4 & 159.2 & 226.9 & 234.2 & 219.5 & 130.9 & 323.5 & 335.4 & 289.4 & 304.0 & 303.8 \\
\hline Session 5 & 186.6 & 184.1 & 299.1 & 157.6 & 246.9 & 364.2 & 192.0 & 229.5 & 322.7 & 277.7 \\
\hline
\end{tabular}

$\mathrm{A} 1=$ athlete $1 \ldots, \mathrm{EE}=$ energy expenditure, $\mathrm{HR}=$ heart rate, $\mathrm{HR}_{\max }=$ maximum heart rate, $\mathrm{MET}=$ metabolic equivalent of task, $\mathrm{TRIMP}=$ training impulse.

roborating previous reports for this population ${ }^{13,29,30}$. Knowing the mean energy expenditure during typical artistic gymnastic training sessions allows better diet control and, consequently, adequate energy supply for gymnasts' growth, daily activities, and athletic performance ${ }^{13}$. Thus, controlling energy balance is crucial to ensure gymnasts' health, preventing menstrual dysfunction, damage to bone development, and injuries ${ }^{13,31}$. Conversely, inadequate energy intake relative to energy expenditure com- promises sports performance and can limit the benefits of training.

WAG is a strength-power activity with specific motor skills, whose energetic requirements are mainly anaerobic in nature due to the high intensity and short duration of competitive routines ${ }^{5,32}$. Thus, the main limitation of this study was that no physiological parameter quantified the contribution of anaerobic metabolism for energy transformation in skeletal muscles. Despite the 
limited use of HR to quantify physiological strain associated with high-intensity intermittent activities, the artistic gymnastic training sessions reported here had a long duration $(4 \mathrm{~h})$, including long recovery intervals. Unarguably, under this condition, the most considerable contribution comes from aerobic pathways, making the current methodology valid and suitable to assess energy expenditure and effort intensity. Future studies should investigate physical and psychological parameters to ensure better characterization of WAG training sessions in young gymnasts.

The results of the current study have some practical applications: (1) the energy expenditure during training sessions may support the prescription of a proper diet according to the gymnast's requirements and (2) quantifying the training load by using HR and TRIMP measures supports training planning and periodization, for example, by comparing TRIMP values over training cycles.

\section{Conclusion}

Young female gymnasts who underwent prolonged $(4.08 \mathrm{~h})$ artistic gymnastic training sessions showed elevated energy expenditure, with average values of $768.3 \mathrm{kcal}$. Moreover, throughout the training sessions, the gymnasts performed efforts that, on average, can be characterized as moderate intensity, reaching average values of $69 \%$ of $\mathrm{HR}_{\max }$. Indeed, gymnasts spent most of the training sessions in intensities corresponding to less than $80 \%$ of $\mathrm{HR}_{\max }$. Altogether, these measurements contribute to characterizing the WAG training demands. Finally, considering the high energy expenditure reported, the training load control of these gymnasts must be accurately ensured.

\section{Acknowledgments}

This study was financed in part by the Coordenação de Aperfeiçoamento de Pessoal de Nível Superior - Brasil (CAPES) - Finance Code 001. The authors also thank the Fundação de Amparo à Pesquisa do Estado de Minas Gerais (FAPEMIG), Conselho Nacional de Desenvolvimento Científico e Tecnológico (CNPq), and Pró-Reitoria de Pesquisa (PRPQ) of the UFMG.

\section{References}

1. Isacco L, Ennequin G, Cassirame J, Tordi N. Physiological pattern changes in response to a simulated competition in elite women's artistic gymnasts. J Strengh Cond Res. 2019;33(10):2768-77. doi

2. Bradshaw EJ, Hume PA, Aisbett B. Performance score variation between days at Australian national and Olympic women's artistic gymnastics competition. J Sports Sci. 2012;30(2):191-9. doi
3. Moeskops S, Oliver JL, Read PJ, Cronin JB, Myer GD, Lloyd RS. The physiological demands of youth artistic gymnastics. Strength Cond J. 2019;41(1):1-13. doi

4. Mkaouer B, Hammoudi-Nassib S, Amara S, Chaabène H. Evaluating the physical and basic gymnastics skills assessment for talent identification in men's artistic gymnastics proposed by the International Gymnastics Federation. Biol Sport. 2018;35(4):383-92. doi

5. Nassib SH, Mkaouer B, Riahi SH, Wali SM, Nassib S. Prediction of gymnastics physical profile through an international program evaluation in women artistic gymnastics. $\mathrm{J}$ Strength Cond Res. 2020;34(2):577-86. doi

6. Sterkowicz-Przybycien K, Sterkowicz S, Biskup L, Zarów $\mathrm{R}$, Kryst $€$, Ozimek M. Somatotype, body composition, and physical fitness in artistic gymnasts depending on age and preferred event. PLoS One. 2019;14(2):1-21. doi

7. Maïmoun L, Coste O, Mariano-Goulart D, Galtier F, Mura $\mathrm{T}$, Philibert $\mathrm{P}$, et al. In peripubertal girls, artistic gymnastics improves areal bone mineral density and femoral bone geometry without affecting serum OPG/RANKL levels. Osteoporos Int. 2011;22(12):3055-66. doi

8. Nunomura M, Pires F. Análise do treinamento na ginástica artística brasileira. Rev Bras Ciências do Esporte. 2009;31 (1):25-40.

9. Debien PB, Oliveira PM, Ferreira T. Training load, recovery and injuries in elite rhythmic gymnasts during main competitive periods: a case study. Sci Gymnast J. 2020;12(3):27785.

10. Marina M, Rodríguez FA. Physiological demands of young women's competitive gymnastic routines. Biol Sport. 2014;31(3):217-22. doi

11. Castagna C, Belardinelli R, Impellizzeri FM, Abt GA, Coutts AJ, D’Ottavio S. Cardiovascular responses during recreational 5-a-side indoor-soccer. J Sci Med Sport. 2007;10(2):89-95. doi

12. Ainsworth BE, Haskell WL, Herrmann SD, Meckes N, Basset Jr DR, Tudor-Locke C, et al. 2011 Compendium of physical activities: a second update of codes and MET values. Med Sci Sports Exerc. 2011;43(8):1575-81. doi

13. Silva MRG, Paiva T. Low energy availability and low body fat of female gymnasts before an international competition. Eur J Sport Sci. 2015;15(7):591-9. doi

14. Léger LA, Mercier D, Gadoury C, Lambert J. The multistage 20 metre shuttle run test for aerobic fitness. J Sports Sci. 1988;6(2):93-101. doi

15. Slaughter MH, Lohman TG, Boileau RA, Horswill CA, Stillman RJ, Van Loan MD, et al. Skinfold equations for estimation of body fatness in children and youth. Hum Biol. 1988;60(5):709-23.

16. Epstein Y, Moran DS. Thermal comfort and the heat stress indices. Ind Health. 2006;44(3):388-98. doi

17. Howley ET. Type of activity: resistance, aerobic, and leisure versus occupational physical activity. Med Sci Sports Exerc. 2001;33:S364-S69.

18. Bot SDM, Hollander AP. The relationship between heart rate and oxygen uptake during non-steady-state exercise. Ergonomics. 2000;43(10):1578-92. doi

19. Wilke CF, Ramos GP, Pacheco DAS, Santos WHM, Diniz MSL, Gonçalves GGP, et al. Metabolic demand and internal 
training load in technical-tactical training sessions of professional futsal players. J Strength Cond Res. 2016;30 (8):2330-40. doi

20. Spencer MR, Gastin PB. Energy system contribution during 200- to $1500-\mathrm{m}$ running in highly trained athletes. Med Sci Sports Exerc. 2001;33(1):157-62. doi

21. Esposito F, Impellizzeri FM, Margonato V, Vanni R, Pizzini $\mathrm{G}$, Veicsteinas A. Validity of heart rate as an indicator of aerobic demand during soccer activities in amateur soccer players. Eur J Appl Physiol. 2004;93(1-2):167-72. doi

22. de Lira CAB, Peixinho-Pena LF, Vancini RL, Fachina RJFG, Almeida AA, Andrade MS, et al. Heart rate response during a simulated Olympic boxing match is predominantly above ventilatory threshold 2: a cross-sectional study. Open Access J Sport Med. 2013;4:175-82. doi

23. Edwards S. High-performance training and racing. Feet Fleet Press, Sacramento; 1993.

24. Rodrigues VM, Ramos GP, Mendes TT, Cabido CE, Melo ES, Condessa LA, et al. Intensity of official futsal matches. J Strength Cond Res. 2011;25(9):2482-7. doi

25. Costa JA, Brito J, Nakamura FY, Figueiredo P, Rebelo A. Using the rating of perceived exertion and heart rate to quantify training intensity in female soccer players. J Strength Copd Res. 2019. doi

26. Lukonaitiene I, Kamandulis S, Paulauskas H, Domeika A, Pliauga V, Kreivyte R, et al. Investigating the workload, readiness, and physical performance changes during intensified 3-week preparation periods in female national Under18 and Under20 basketball teams. J Sports Sci. 2020;38(9):1018-25. doi

27. Haddad M, Chaouachi A, Wong DP, Castagna C, Chamari $\mathrm{K}$. Heart rate responses and training load during nonspecific and specific aerobic training in adolescent taekwondo athletes. J Hum Kinet. 2011;29(1):59-66. doi

28. García-Ramos A, Feriche B, Calderón C, Iglesias X, Barrero A, Chaverri D, et al. Training load quantification in elite swimmers using a modified version of the training impulse method. Eur J Sport Sci. 2015;15(2):85-93. doi

29. Soric M, Misigoj-Durakovic M, Pedisic Z. Dietary intake and body composition of prepubescent female aesthetic athletes. Int J Sport Nutr Exerc Metab. 2008;18(3):343-54. doi

30. Sweeney EA, Daoud AK, Potter MN, Ritchie L, Howell DR. Association between flexibility and low back pain in Female Adolescent Gymnasts. Clin J Sport Med. 2019;29 (5):379-83. doi

31. Nattiv A, Loucks AB, Manore MM, Sanborn CF, SundgotBorgen J, Warren MP. The female athlete triad. Med Sci Sports Exerc. 2007;39(10):1867-82. doi

32. Jemni M, Sands WA, Friemel F, Stone MH, Cooke CB. Any effect of gymnastics training on upper-body and lower-body aerobic and power components in national and international male gymnasts? J Strength Cond Res. 2006;20(4):899-907. doi

\section{Corresponding author}

Karine Naves de Oliveira Goulart. Universidade Federal de Minas Gerais, Av. Antônio Carlos 6627, Pampulha, Belo Horizonte, MG, Brazil.

E-mail: karinegoulart91@gmail.com.

Manuscript received on June 17, 2021

Manuscript accepted on November 1, 2021

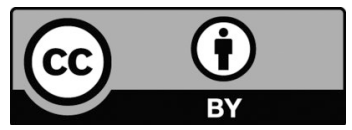

Motriz. The Journal of Physical Education. UNESP. Rio Claro, SP, Brazil - eISSN: 1980-6574 - under a license Creative Commons - Version 4.0 